\title{
加强与提高基层水利工程质量管理水平的路径
}

\author{
吴瑞卿 \\ 安康市水利工程技术中心
}

DOI:10.32629/hwr.v3i10.2430

[ 摘 要] 质量问题一直是基层水利工程建设的核心内容, 故而就有必要严格遵照相关标准规范开展施工,全面落实质量管理工作。然而, 受到各 方面主客观因素的影响,基层水利工程建设质量管理落实效果不够理想。本文主要分析了基层水利工程质量管理存在的问题,并提出了相应的解 决策略,以供借鉴。

[关键词] 基层水利工程; 质量管理; 解决策略

与西方发达国家相比, 我国基层水利工程建设较为落后, 水利工程质 量管理也存在诸多问题, 如质量管理落实不到位、政策执行率偏低等。对 此, 各基层水利工程管理部门应加大对质量管理工作的重视力度, 不断提 升综合管理水平。

\section{1 基层水利工程质量管理的内容}

我国基层水利工程质量管理问题较复杂, 制约因素较多, 管理难度系 数较大。要想保障基层水利工程质量, 首要任务是明确监督管理内容, 然后 进一步明确管理标准细则, 逐步完善质量管理薄弱环节, 全方位动态化协 调控制整个水利工程施工流程, 实现质量安全目标。

\section{1 工程前期准备工作}

只有积极做好前期准备工作, 才能促进水利工程建设的正常运转。尤 为关键的是在工程开始前要签署相关文件资料, 进一步明确双方的职责权 限划分, 以免责权混乱, 互相推诿, 引发不必要的纠纷。且高度落实工程质 量管理工作, 综合评估施工方的专业技术水平, 加大原材料质量检测力度, 杜绝 “豆腐渣工程”。

1.2 工程建设管理工作

理措施。并认真客观地记录水利工程质量检验的基本情况, 整理质量检验 记录, 从而深入了解工程的运行概况。

3.2 加大资金支持力度

部分小型水利工程施工中需要大量的资金支持。为了获得更加充足的 资金, 首先要拓宽筹资渠道, 融入地方财政。其次, 地方政府需积极争取中 央财政的支持, 为工程建设提供资金保障。最后, 调动当地居民的积极性, 使其可更加主动地投身于水利工程建设和施工中, 最大限度地发挥政府资 金的积极作用。

\section{3完善技术人员的综合素质}

技术人员的综合素质对工程质量管理的效果有着十分显著的影响。为 了提高技术人员的综合素质, 应当组织技术人员参与系统全面的培训活 动。基层水利部门的技术人员在日常工作中要主动参加业务和技术培训, 从而不断增强自身的专业能力。再者, 要组织技术人员开展业务交流与探 讨, 学习和借鉴发达地区水利工程建设单位及人员的工作经验, 从而完善 管理制度, 优化技术人员的综合素质。同样重要的是, 基层水利施工单位需 完善员工的福利待遇, 以期吸引更多专业人才, 且加大人员考核力度, 如未 通过考核, 则该人员要接受继续教育与培训。

\section{4 重视质量监管}

加强基层水利工程施工细节监督可有效提高工程的施工质量, 从而不 断优化工程管理工作。基层水利工程质量管理人员应在工程施工前认真审 核工程图纸和工程预算, 确保工程设计和施工的顺利进行。且严格控制建
在基层水利工程施工进程中, 要逐步细化管理内容, 明确管理事项, 推 行专人专管制度, 实时监督责任制度执行情况。另外, 全方位动态监督整个 施工流程, 协调解决施工现场出现的各类问题, 并构建完善的质量监督反 馈体系, 接受合理化建议。

1.3 工程建设质量检测工作

质量检测是水利工程施工完毕后的重要环节。只有通过检测的水利工 程才是真正的合格工程。为此, 验收方需严格遵照国家法规与行业制度进 行验收, 保证技术报告与质量报告的完整性与真实性, 以免不合格工程直 接投入使用。另外, 实时监督整个质量检测流程, 以免检测人员责任意识淡 薄, 故意降低标准。

\section{2 基层水利工程质量问题诱因}

2.1 工程管理手段落后

据相关调查报告显示, 基层水利部门的质量保护体制有待完善, 这也在 一定程度上影响了质量监控方法的落实效果。具体表现如下: 部分施工方盲 目追赶工程进度, 质量管理方案不合理, 使得工程质量缺乏保障; 水利工程施 工问题处理不到位, 将工程私自转让承包。现阶段, 基层水利工程施工环节存

筑的原材料, 使用的材料必须满足建筑图纸的要求, 其质量和性能要与工 程施工的要求相符。不仅如此, 要增加资金支持, 为群众讲解基层水利工程 的积极意义, 做好筹资工作, 并引进先进的技术和设备, 改进工程施工质 量。同时认真检查已经完工的部分, 避免发生安全事故。

3. 5 坚持现代化方向

以现代化的理念指导基层水利工程管理实践, 以现代化的技术装备武 装和改造水利基础设施, 以现代化的管理提高水利效益, 以新技术、新工艺 和新材料提升水利建设与管理的科技含量, 以信息化促进水利建设与管理 的现代化。

\section{4 结束语}

当前, 我市水利工程建设事业持续发展, 基层水利工程建设也取得了 较大的进步, 但是在基层水利工程质量管理中, 依然存在着明显的不足。对 此, 应采取有效措施, 解决当前存在的各类问题, 加强质量管理的有效性, 以此推动工程建设的顺利完工。

\section{[参考文献]}

[1]苏文斌.新形势下基层水利工程质量监督工作存在的问题与对策 [J].农业科技与信息,2018,(14):83-84.

[2]郭宏斌.基层水利工程质量管理的优化措施研究[J].工程技术研 究,2019,4(04):158-159.

[3]郑航.新形势下基层水利工程质量监督工作中存在的问题与对策 [J].水利科技,2015,(01):67-70. 
在分包与隐性转包等情况, 且承包方资质不完备, 威胁工程质量安全。

2.2 专项投资资金贵乏

部分水利工程建设资金属于基层自主筹集的资金, 整体投资力度贵乏, 且水利工程基础配套设施建设不完善。基层水利工程检验缺少精密化的监 视测量仪器, 而且高素质的监测人员极度贵乏, 单纯依靠以往积累的经验 开展水利工程建设监督工作, 使得监督工作落实效果不够理想, 工程质量 监测水平始终停留在初期发展阶段。

2. 3专业技术薄弱

伴随市场经济的繁荣发展, 基层水利工程项目数量与规模不断扩张。但 是基层水利技术人员专业素质较差, 无法满足工作需求。且西北部偏远山 区工作环境恶劣, 条件艰苦, 难以吸引高素质的技术人员参与建设, 这使得 各地区的建设水平存在较大差异。再者, 基层水利技术人员的工作繁琐复 杂, 工程质量监督管理的专业学习时间有限, 施工人员综合素质贵乏, 难以 胜任难度较高、要求较高的工程检测工作。

2. 4质量监管投入力度不足

从施工持续时间方面来说, 水利工程建设并不是长期性工程。然而, 只有加大监督与检测力度, 从工程的各个环节入手, 才能从根本上提升水 利工程质量安全等级。纵观基层水利工程建设现状, 专项投资资金与专业 人才供应贵乏, 导致综合监管水平偏低, 无法保障水利工程质量。

\section{3 提升基层水利工程质量管理水平的具体策略}

水利工程建设与农业经济发展息息相关, 而我国作为农业大国, 基层 水利工程建设显得至关重要。与此同时, 全面落实基层水利工程质量管理 工作具有实际意义。具体内容如下所述。

3. 1 构建完善的质量管理体系

首先, 各个行业都有各自的规章制度, 而基层水利工程质量管理制度 则是保证工程建设质量的先决条件。合理分配各部门的任务, 是提高工程 建设质量的关键举措。各部门应各尽其责, 做好分内事, 不断完善质量检测, 提升综合管理水平。

其次, 优化基层水利工程质量检测制度。要想改进工程建设质量, 就需 强化水利工程质量检测, 尤其是质量法人检测。为协调解决工程质量安全 问题, 需在最短时间内查明危险因素, 并采取行之有效的处理措施, 从根源 上解决工程质量问题。

最后, 认真记录水利工程质量检测报告。归纳分类工程质量检测报告， 为工程质量排查提供必要的参考依据, 同时, 保证各项质量保障措施的有 序运转。

3. 2 提升水利工程管理科技化水平

在常规管理工作过程中, 要转变思想观念, 采取科学合理的管理方式。 为保证基层水利工程管理的先进性与科技性, 应当拓展水利通信渠道, 整合 资源, 构建完善的通信网络体系、水利资源数值库、水质量检查系统、通 信评估系统与防汛指挥系统, 以此全面提升水利工程管理的科技化水平。
总而言之, 施工企业要进一步优化水利工程管理的综合水平, 进而为推动 水利行业的良好发展奠定坚实基础。

3. 3加大投资力度

部分小规模水利工程的建设, 往往需要投入大量的资金。为满足水利 工程建设的资金需求, 应采取如下几方面措施:

其一, 拓展投融资渠道, 加大基层政府的财政投资力度; 其二, 各基层 政府部门要充分发挥宏观调控优势, 尽可能的争取中央财政部门的扶持基 金, 满足资金供应需求; 其三, 积极鼓励广大人民群众参与水利工程建设, 高度发挥政府鼓励政策的优势效能。但是在基层水利工程建设进程中, 在 储备资金短缺的情况下直接开展施工, 会出现 “头重脚轻” 的情况, 则需要 依靠财政部门的资金分配维持水利工程建设。

3.4 提升技术人员专业水平

要提高水利工程技术人员的专业水平, 就需采取如下几方面措施:

首先, 加大基层从业人员的培训投入力度。对基层水利部门的从业人 员来说, 应定期组织业务培训与职业素质教育, 在潜移默化间提升专业技 术水平, 强化职业道德素养; 其次, 加强业务交流。践行 “三人行必有我师” 的思想理念, 汲取发达地区水利工程建设单位的经验; 最后, 构建完善的人 员管理制度, 适当提高员工准入门槛。基层水利部门需秉承与时俱进的基 本原则, 全面推行优惠政策, 吸引高素质的专业人才。同时, 加强从业人员 考核管理, 将不合格人员调离工作岗位, 或者直接辞退, 优化内部人力资源 配置。

3. 5 调整监控方法, 优化综合检测水平

水利工程质量检测是评估工程质量, 校验工程质量安全的重要环节。 为此, 各基层水利管理部门要不断完善监控技术, 提升专业检测水平。施工 方为保证水利工程建设质量, 往往会购置一整套检测器材, 并配置专业的 检测人员。且严格检查工程材料质量。在施工过程中, 需定期抽检, 以免使 用不合规、不合格材料。此外, 在质量检测过程中, 相关人员要如实记录检 测数据, 生成完整的检测报告, 避免不必要的纠纷。

\section{4 结束语}

综上所述, 基层水利工程建设是国民经济体系的重要支柱产业, 提高 水利工程建设质量具有实际意义。为此, 基层水利工程管理部门要加强技 术人员培训, 完善其专业技能, 科学解决质量管理中存在的各类问题, 加强 监管有效性, 以此推动水利工程建设事业的良好发展。

[参考文献]

[1] 任睿. 浅谈基层水利工程管理的重要性 [J]. 建材与装 饰,2017(08):270-271.

[2]许卫东.关于加强基层水利工程质量管理的思考 [J].绿色环保建 材,2017(03):236.

[3]辛立申.浅谈基层水利工程管理的重要性 [J]. 科技创新与应 用,2016(05):206. 